\title{
The Team Using Video Games To Help Fight Climate Change
}

\author{
Marc Rigaudis \\ Jiwe Interactive Limited, Kenya \\ Max Musau \\ Jiwe Interactive Limited, Kenya
}

\begin{abstract}
Extracts of the interview of Max Musau and Marc Rigaudis by Faustine Ngila Nation Newspaper Nairobi KENYA
\end{abstract}

... Max Musau, former head of innovation at United States International University Africa (USIU) in Nairobi and Marc Rigaudis former Film Production director at the same university have teamed up to develop a video game to get the conversation of climate change and futurism active -- even among the young.

Dubbed Jiwe Studios, the online game downloadable from the web is the meeting point of literature and technology, equipping children with digital skills as they play a game based on the current geo-political happenings, where Africa has become the battleground.

... In Marc Rigaudis's screenplay titled Usoni (Swahili for 'the future'), he paints a picture of a Global North ravaged by the effects of climate change, forcing populations to seek refuge in the Global South - Africa.

In his 160-page piece of art, Ophelia, the protagonist, initially from the El-Molo community in Kenya, runs away from her Paris home, and starts to trace her way back to her motherland...

In an apocalyptic vision in 2063, Rigaudis foresees that Europe is covered by a black cloud and the sun has disappeared. Following a chain of catastrophes mainly caused by human abuse, Mother Nature reacts in a grand finale with all the volcanoes erupting, blocking the sun, blocking life. People from the North have to escape to the South, to Africa, where the sun still shines.

A pure analogy with what is happening nowadays with many Africans trying to cross the Mediterranean sea and too often losing their life because the African sun which burns their skin is not shining for them! $A$ replica of what is happening now but in complete reverse.

Keywords: Video Game, Africa, Woman, Climate Change, Injustice.

\section{Introduction}

Kenya's gaming enthusiasts, creatives and innovators are teaming up to combat climate change with video games.

According to Mr Musau, himself a lover of video games, telling the African story through a 30-minute video game is one of the best ways to let children comprehend the value of a healthy environment.
"There will be a new scramble for Africa if Western powers continue to pollute the environment. The conversation around electric cars is what Africa needs. Children need to learn that reducing carbon print is key to the future survival of mankind," he says.

With the gaming industry projected to surpass Sh200 billion by 2023 according to Newzoo, the duo aims to get Africa talking while tapping on Kenya's high smartphone penetration and lowering the cost of mobile internet.

"Africa has been listening to the world for too long, it's high time Africa starts talking to the world..." notes Mr Rigaudis.

\section{USONI THE BOOK.}
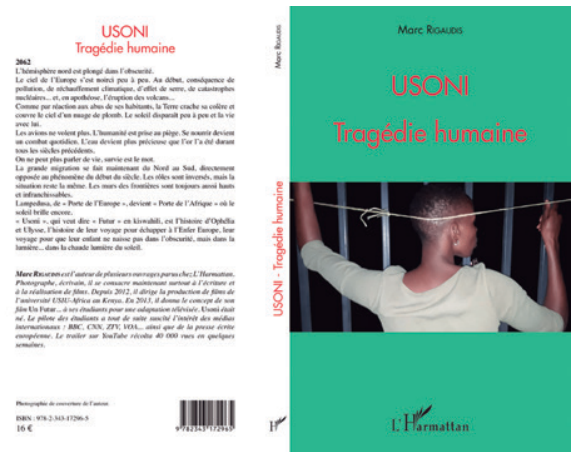

Image 1 - Usoni press kit

\section{WHY USONI}

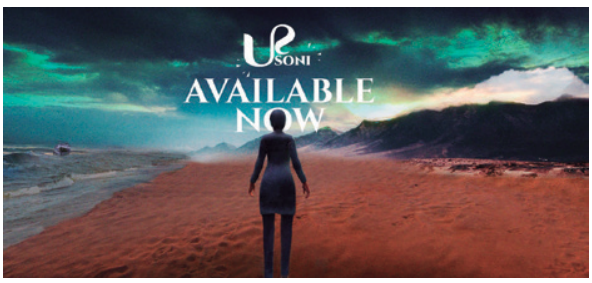

Image 2 - Usoni the game release poster

USONI, swahili for 'future' is a home coming story for the main character Ophelia, back to Turkana, Kenya, a place where she has never been and where her father and revered leader left decades earlier. Set in the post apocalyptic time where the Sun has lost its shine, she struggles to find a way back home and hold on to the love of her life. In 2020, the world is strained under the weight of pollution, climate change and a 
once in a lifetime pandemic, the world's inequality at an all time high, a world inching towards the end of calamity brought about by the excesses of an elitist and rampant political upper class, they created race wars and gender injustice across almost all nations to divide people. It is under this backdrop that the journey of Ophelia becomes more relevant and the warning even more dire. Usoni tells a story of the results of pollution, environmental destruction and runaway greed. Pollution and environmental destruction that was caused by the runaway greed of the elites of the world, who drained the world of its natural resources and polluted what remained, to line their pockets and to make their already comfortable lives ultra luxurious and decadent. Usoni is a fight against extreme circumstances, and the desire of the human spirit to survive. It is our responsibility to awaken this spirit and use Usoni as a cautionary tale to be avoided, rather than a prophecy of the future that is to come. It is our responsibility as every citizen of this planet, to rise up and fight against pollution, and unnecessary plunder, and misuse draining the world resources that is changing the balance in the world. If we don't do it, no one will.

\section{STORY OF EL MOLO}

USONI was born from a journey to the EI Molo land... the Lake Turkana. It's in the last years of the 20th century that I came across a book by a French author, ex singer of "my youth" whose music I used to enjoy listening to. The title was "Le Voyageur Magnifique" in English: "The Magnificent Traveller". The story: a man decides to travel around the world to visit the sites of what he calls "The Beginnings", there were four of them... one of them was Lake Turkana! Why Lake Turkana? The reason comes from a skeleton. The skeleton discovered by a team of scientists on the side of the lake, the name, Lucy, comes from the period in time. The Beatles are dominating the music of the planet. Their universal song "Lucy in the sky with diamonds" gives the perfect name to the first woman to stand on her legs and raises her eyes towards the sky. For the author, this represents a beginning. The Beginning... the beginning of Humanity and the Lake Turkana is the Cradle of Humanity! Lake Turkana fascinated me and when I had the opportunity to come to Kenya, more than the incredible wildlife or the extraordinary landscapes that you can find there, my focus was on the Sea of Jade. When I did some research about the lake, the El Molo tribe popped in right away. For certain specialists, it was the smallest tribe, with, according to some sources, a population of fifty or less, diminishing day after day... on the way to extinction. Then, here it was... I had some humans becoming extinct in the same place which had seen the beginning of humanity. It was enough to make me go there and to capture what is left of this Elmolo culture before it disappears all together. A team joined me and we set off for one of the most incredible journeys I ever did. Going to Lake Turkana was like reversing time. The road was extremely difficult, and sometimes there was no road at all. We went through the most amazing landscapes, meeting the most amazing people and somehow the most beautiful people... people from another age. The Pokots, the Samburus, the Turkanas, all these tribes have their own culture, their own dignity, their pride although in the eyes of our society they have nothing! The best representation of what I mean was the Elmolo. The El Molo have nothing but in a way they have everything. Difficult to understand that when you look at their tiny little huts, bamboo-made, a very poor protection from the ever present, scorching sun, inflexible master of the area, one of the hottest places on Earth. We recorded El Molo for the first time and I named the film "The Last Song' then it became the seed which germinated almost twenty years after and bloomed into Usoni. It is from the El Molo that I got the legend of the first woman, the one who created the lake, the one that the Ancients call in their sacred song, the Mother of the El Molo, as if to say the Mother of Men...Yes the Last Song set the first stone of Usoni. The Last Song made me meet and work with one of the characters I created from reality. Lion Lepalo, fighting to save his Lake, became in my story the main character's grandfather. Ophelia, in Usoni, will have to follow the road set up by her grandfather, the road which starts in the suburbs of Paris to end in the splendor of the Sea of Jade.

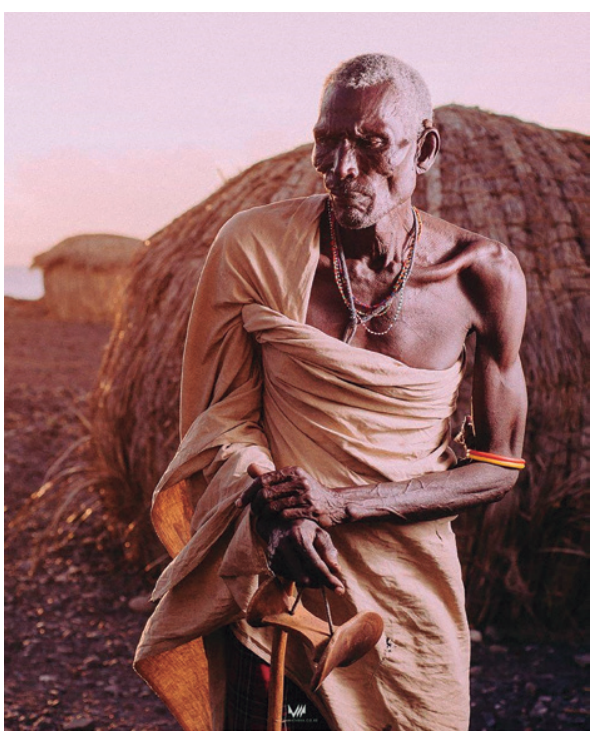

Image 3 - El Molo tribe male figure

\section{USONI}

After the great climate catastrophe of 2035, the seas are higher and more violent than ever before. A series of huge volcanic eruptions and massive earthquakes have shattered established life systems across the Northern hemisphere. All the world's nuclear reactors melted down or were washed into the sea. For years the skies have been covered with dark clouds of radioactive 
smoke and ash, and the air, seas and freshwater lakes have become polluted. A super powerful organization has the global monopoly of water and totally controls the world...Global, social and economic order and ordinary life has disintegrated completely. It's every man and woman for themselves. In an ironic reversal of fortune, now immigrants from the West risk their lives to travel over treacherous seas to Africa where the sun still shines, and there is life and hope.

In the USONI scenario, the Northern Hemisphere is experiencing many disasters related to climate change, pollution, ultra-industrialization, in short, many of the same things that are generally joining the same and only thing: the pursuit of profit in spite of humans. Through all these injustices managed by a system that slowly but surely led the world to its loss, after all this, after all these abuses, Mother Nature decides to strike a big blow. It's The Great Catastrophe of 2037. All the volcanoes (... of France and Navarre) erupt, covering the sky with a thick black cloud. The sun disappears and life with it.

\section{WHO IS OPHELIA}

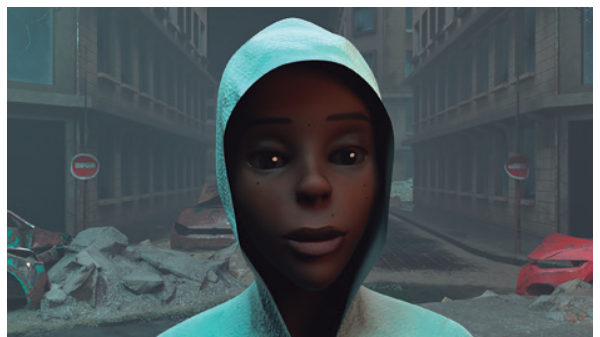

Image 4 - Ophelia in Usoni the game

In the world of USONI, Ophelia is a kind of anti-system model, a free woman, walking outside the box, an altruistic individualist, a positive rebel... a resistant. The first images of Ophelia are those of a humble, modest woman whose only ambition is to give birth to the baby she carries within her under the African sun and not in the land of shadows that France has become. Paris, once the City of Lights, is in 2062 the city where the light has gone out forever. The analogy with what has been happening for years for women "from the south", especially in Africa where in some countries, women have no choice but to flee their homes to give their children a chance of survival... to go and find the sun that has disappeared from their lives. For how many women this sun of Africa no longer shines! This sun may burn their skin, dry their lips, kill their cattle, but it does not shine for them. And they think that the sun can shine for them in green Europe... a bitter disillusionment in most cases! Ophelia was born in darkness, in a world from which light has disappeared. Usoni is the story of her journey to the light. She carries life within her, like any pregnant woman, but in Ophelia's case the symbol goes much further, much higher...Ophelia carries within her the life of a world that will completely disappear in favor of a world system that has imposed its values - non-values rather - leading to the destruction of humanity. On her way to Lake Turkana, Ophelia will transform herself from a simple woman who does not want her baby to be born in the dark into a unifier of the people of the world, freeing them from the yoke imposed by a system. The System has made the whole world its slave, replacing the whip with profit, money, power? By bringing together all spheres of the population, Ophelia creates a tsunami that nothing can stop. For just as one cannot stop the water that rises or the rain that falls from the sky, one cannot stop a people that unites to walk forward, towards the future..."Usoni “...Ophelia discovers herself as the unifying heroine of the world that the System had succeeded, in a few centuries, in splitting in two, digging a chasm between "those who have everything and too much" and "those who have nothing or too little". By opening the gates of Turkana City, it forces the System to abdicate, opening the way for the rest of the world. The story of Ophelia is a fairy tale that has no political, scientific or philosophical pretensions, but rather a hope for the overthrow of the world, the end of a world that is too unjust. It is also a mad hope of revolution of humanity of all colors overthrowing a system also of all colors and which leads the planet Earth to its loss. Yes it is the hope of the utopian world of John Lennon's song "Imagine"... a world that could have been, should have been, could be, should be, can be, will be... " Usoni “...

\section{ULYSSE CHARACTER IN USONI}

Ulysse' character was created from the real life of Stephen Wiltshire.

Ulysse was born autistic in 2010. At 4 he could draw details of complex architecture after looking at it only once. At 9 he says his first word : "paper", after his teachers provoked him by confiscating his drawing tools. At 19, through his art, mainly reproduction of architecture, machinery, robot, high tech etc. he is approached by some Al leaders, part of the international organization called "System". He becomes a recognized genius indispensable to superpowers. For 7 years he is enslaved by the System in a kind of Silicon Valley to produce and develop Al to manipulate the human mind in order to control the world. Ulysse takes the advantage of the 2037 Great Catastrophe to escape and, helped by adversaries of the System, starts a long, fugitive journey across Europe in chaos. He must hide from the System which wants to bring him to Africa where they want him to continue his work on Al. The System, now established in New World Africa, wants to maintain its power on the world. The main strategic center of the High Commandment is Turkana City, a glass fortress built on top of the Turkana Lake. Ulysse ends up in half destroyed Paris. The meeting with Ophelia is like the fusion of two bodies and minds, like two pieces of a puzzle which perfectly fit. The child to come is the symbol of why they got together, of what seemed to be their destiny. Now Ulysse is ready to go to Africa, not to work for the System but to fight it. 
Although Ophelia doesn't know yet of her mission, she right away feels that Ulysse came into her life to rescue her. She doesn't realize yet that, by following Ulysse in their race towards the sun, by promising to herself that her baby will be born under the sun and not in the darkness, she will be the one who will save the world...

\section{WHEN THE CORONAVIRUS PANDEMIC SITUATION JOINS USONI}

It was in 2010, 10 years ago, that I started thinking about this science fiction scenario, which, in fact, was based on facts that happened every day. Like everyone else I watched these boats full of men, women and children, who had a good chance of ending up at the bottom of the water of our beautiful Mediterranean Sea, turning it into a terrible and huge cemetery. And I thought what an injustice! Yes, what an injustice! desperate people, so desperate that they don't hesitate to take all these risks to flee their native lands for lands that they think are greener but that in most cases in fact turn out to be only burnt land for them... if they can do it !

It is from these thoughts that I began to imagine a world upside down. A world where, all of a sudden, people would no longer try to flee the South to reach the rich plains of the North but instead they would leave the devastated North, which became a black and cold zone to reach the South where life, worthy of the name, would still exist.

In the USONI scenario, the Northern Hemisphere is experiencing many disasters related to climate change, pollution, ultra-industrialization, in short, many of the same things that are generally joining the same and only thing: the pursuit of profit in spite of humans . Through all these injustices managed by a system that slowly but surely led the world to its loss, after all this, after all these abuses, Mother Nature decides to strike a big blow. It's The Great Catastrophe of 2037. All the volcanoes (... of France and Navarre) erupt, covering the sky with a thick black cloud. The sun disappears and life with it.

And this is where the coronavirus pandemic, with a magic wand of a bad fairy, joined my sci-fi scenario. With confinement the sun has disappeared from the lives of millions, perhaps billions of humans. This sun, they can only see it through the glass of their windows or on their screens. This little virus microbe did more than any major volcanoes could have done. He put the whole world in the shade. Yes "in the shade", as they say when you put somebody in prison. Yes confinement is prison and yes it is the only solution!

In his letter, Moustapha Dahleb wondered "how a microscopic little thing... is disrupting the planet".

Yes how indeed... but could it be that is in order for our children not to know the End of THE World there but the End of ONE World!

\section{WHEN WANGARI MAATHAI'S FIGHT JOINS THE USONI SCENARIO}

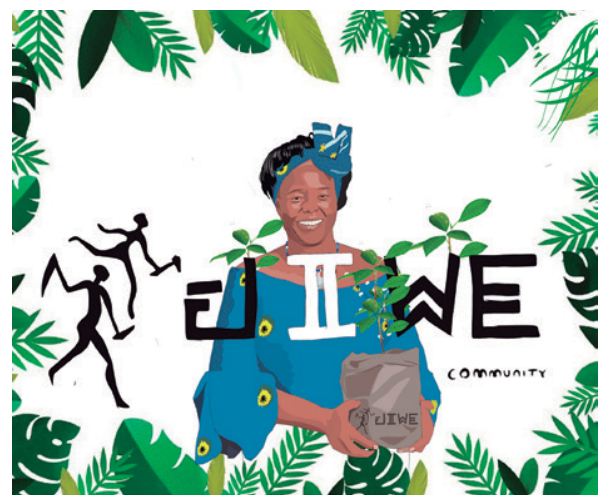

Image 5 - Wangari Maathai

I was working with Wangari Maathai after she received her Nobel Peace Prize for environment conservation. She was explaining that conflicts and particularly tribal clashes in Africa, more specifically in north of Kenya, are mostly the consequences of food and water shortages... if you don't have food to give your children, if they don't have any water to drink, if they are dying, what else is left but jumping over the wall to get the food and water from your neighbor... basically a man becomes extremely dangerous when in desperation, more so when he feels he has nothing to lose... not even life!

This kind of reflection must have led me to start writing a film about the injustice that has driven the world through so many centuries. When a world decided to dominate, abuse, rape, under the pretext of "civilizing" people who happened to be "different" and... unarmed except for some spears and arrows. As a justification for treating people like cattle, sometimes worse than cattle, as is the case in slavery for instance, which makes it more acceptable to deem these people inferior, inhuman, possessing smaller brains and... black skin. Thus marked the birth of 'Colonialism and imperialism', 'racism and segregation', which in many ways and different forms, are still very much prevalent!

In deep reflection over how unjust the world has been for the majority of its population, I started imagining a world in which the situation would be reversed. There were frequent reports regarding Africans losing their lives in desperate attempts to transverse the sea to gain entry into Europe. This was the starting point of my scenario. How was it possible that Africans, living in a continent with the richest natural resources on earth, would take such risks for themselves and their families? In the hope to find a better life or at least work so they could have a life! 
What if the North hemisphere, the First World would suddenly transform into the Third World? What if living became unbearable in Europe and the people started moving from North to South? What if they encountered the same hardship trying to get into Africa as do Africans currently face crossing the sea to get to Europe, supposed land of opportunities and a better life! What if they face the same danger, hassles and abuse that the Africans endlessly encounter when and if they get to Europe.

Usoni is by far not a story of vengeance of the third world against the developed world.

In my scenario, it is the same system, created and manipulated by a minority of the world population. This clique encompassing all races and creed holds the power and influence that led to the creation of the third world. They are the first to escape into Africa still bearing the same power and influence. Then, with their African counterpart, they shut down the continent to the now miserable European populace.

This is what USONI is about. The injustice that drives people to search for the sun when it has ceased to shine for them. The metaphor is apparent for numerous people. The sun might be burning their skin but is not shining for them anymore. And they come to Europe to find a sun which unfortunately sometimes is not to be seen...

\section{When John Lennon's “IMAGINE” joins USONI's scenario}

In fact it should be the opposite" When Usoni's script joins John Lennon's Imagine.

John Lennon's universal song has resonated with humanity around the world for more than half a century, carrying his message of peace, justice, brotherhood. A utopian message, certainly, but a very powerful one that has moved millions, perhaps billions of people like me. Who has not been carried away by the languid melody and the wonderful words of wisdom? Wisdom that, unfortunately, can only remain utopian in our world today.

USONI's scenario begins with an upside down world where, among other things, migration after disasters in the northern hemisphere is from north to south, and no longer from south to north as it is nowadays. So we can believe that in fact the story is only about this enormous injustice: thousands of desperate people throw themselves into the water to try to cross a sea that too often becomes their graveyard.

But the injustice in the world does not stop there. Injustice has reigned over the world for centuries, deepening inequalities, hollows that too quickly become veritable abysses, relentlessly separating two worlds that no longer have anything in common. A system that has firmly established itself at the top of the world to enslave it to its power. A system that has not hesitated to flout true values, to abuse nature for mercantile purposes, to sacrifice the planet, to take entire populations, and even future generations, hostage.

In the script there is a passage where Ophelia, the main character of this utopian tale, meets a wonderful world where everything is perfect, where everything is as it should have been... or should have stayed. A world without borders, without difference, without religion, without war... the world of "Imagine" and by the way John Lennon is revered there as "Mami Watta", next to Wangari Maathai, Nelson Mandela, Masanobu Fukuoka, Martin Luther King and many others who changed the world or at least tried to change the world. These Mami Watta, like John Lennon, brought to their peers another vision of the world that was possible, sometimes by their actions, sometimes by their words, sometimes by the sacrifice of their lives.

"Imagine" sings of a world as it could have been, should have been, could be, should be, the fantastic story of Ophelia tells of the flight from a lost, sacrificed world to a world that would unite two worlds into one, a world that would be better for all... yes it is again, not the end of THE world but the end of ONE world...

"You might say I'm a dreamer but I'm not the only one..."

\section{USONI THE GAME}

\section{Points we considered.}

\section{Graphical Quality}

One of the main differentiators when considering Unity vs Unreal Engine is the quality of visuals. Unreal offers high-fidelity visuals straight out of the box, whereas Unity - while still able to produce high- quality visuals - takes a lot more work to get your assets looking close to the same level as Unreal. And even then, it won't produce quite the same quality.

\section{Learning Curve}

This is where Unity shines. With its simplified interface you will be able to create something in no time and not to mention tons of learning materials that are freely available. Unreal Engine is quite intimidating to a beginner. It's interface has so much that would make a new user quit but once you get used to it, it is really simple to use. The learning materials are also freely available.

\section{Target Platform}

Unity has much better cross-platform integration. It enables you to deploy your game across all major mobile, VR, desktop, console, and TV platforms plus the Web. The supported platforms include Android, iOS, Windows Phone, Tizen, PC, Mac, Linux, PS4, Xbox One, PlayStation Mobile, PlayStation Vita, Wii $\mathrm{U}$, tvOS, Android TV, and Samsung Smart TV. Native 
support is available for major VR platforms including Oculus Rift, Gear VR, Playstation VR, Microsoft HoloLens and Steam VR/Vive.

When it comes to mobile games, that is where Unity really shows its dominance. With many popular mobile games created with Unity, it's really become a mobile developer's go-to game engine.

Unreal Engine also supports all the platforms that Unity does but its down side that it requires high end devices mostly and Unity can work on both high end and low end devices

\section{Scripting}

Unreal Engine uses both $\mathrm{C}++$ and Blueprints. Most people find that $\mathrm{C}++$ is a bit difficult to learn and implement but the Unreal Engine Visual Scripting Language (Blueprints) is easier and friendlier to anyone who has never programmed/coded before.

Unity uses $\mathrm{C \#}$ as its scripting language but it also supports Javascript. Unity has no integrated visual scripter, but there are a number of 3rd-party options available such as: Bolt (now free with future integration planned for the engine) and Playmaker.

\section{2D Games}

Unity is the best tool for creating 2D content. With its simplified $\mathrm{UI}$ and very well developed $2 \mathrm{D}$ tools, intuitive sprite animation etc - you really can't go wrong with Unity.

It can of course be done in Unreal as well, but there just isn't much point as Unreal is not developed for 2D games. It will add an unnecessary level of complexity that just simply isn't needed.

\section{3D Games}

Unreal is the best tool for creating 3D Content especially if you need great visuals. The workflow of working with $3 \mathrm{D}$ is integrated really well. Unity $3 \mathrm{D}$ also works well with $3 \mathrm{D}$.

\section{Visual Debugging Tools}

Unreal Engine has better access to visual debugging, you can easily test what, when and how is being drawn, you can control the whole process and monitor how much time is spent on a certain element.

Unity Visual Debugging Tools are as integrated as Unreal and some of them you have to access through the unity asset store.

Advantages to publishing across (PC, PS, Xbox, Nintendo, Android, and Web)

Both Game engines can publish to any platform these days. A choice of platform depends on how the game was designed. Some gameplay elements work on a certain platform than on others. It also depends on who the target audience for the game is.

In Conclusion, there is really no advantage to publishing on any platform. It really depends on how the game was designed and the target audience.

\section{Game UI and Audio Unity's system}

Understanding that we were building off an already rich storyline line USONI gave us an edge, we did not have to start thinking about the storyline from scratch. So building the story we decided to start with designing 4 gameplay scenes that are exciting and fit into the story plot.

We started with the game controller navigation. At first we used multiple game canvases, which is the system used in building UI in Unity, in different scenes which ended up causing a few issues. This is because when switching between multiple canvases the initial selected item for example a menu button is retained so when in another canvas and that initial menu button isn't there functionality is lost. We resolved it by using one canvas to avoid the switching.

We then created the foundation script which will set up the game's audio manager that will hold all of the game's audio clips, dialogue and sound effects which definitely add depth and meaning to any game. The audio manager plays sounds at the required times while also controlling it's volume and pitch throughout all the scenes.

\section{Dialogue System}

There were several tools to help with creating dialog systems, we researched a few: (Twine,Yarn spinner and Ink) and picked Yarn Spinner. Yarn Spinner helps you build branching narrative and dialogue in games. It's easy for writers and developers to use, and has powerful features for integrating your content straight into your game.

We used Yarn Spinner to create a dialog UI (displays the conversation) in the scene and used TextMesh Pro which uses advanced text rendering techniques along with a set of custom shaders, delivering substantial visual quality improvements while giving users incredible flexibility when it comes to text styling and texturing. At the end we added a dialog script to handle when to display the dialog UI and when not to.

We also used an indicator for dialog and that would also be attached to the Al Buddy. The UI indicator has a script that ensures it always faces the camera as setting a standard camera angle for conversations makes for a better gameplay experience. The script also handles when the Al buddy can or cannot talk, in our case our main character has a companion whom they frequently dialog with.

\section{The Al companion}

In Usoni the Al buddy is in most cases Ophelia because in the game you play as each of them in different parts of the game but Ulysse has the most user interaction for the first part of USONI. 
We created the Al buddy system in the game for the player to have a companion in the game as in the original story. The companion accompanies the player throughout their journey in the game. The Al buddy consists of a rigid body, navigation mesh, navigation mesh agent and an $\mathrm{Al}$ buddy script. The rigid body helps to add physics to bodies, while the navigation mesh agent allows the $\mathrm{Al}$ to navigate the scene using the navigation mesh (an area in which the $\mathrm{Al}$ can move) and the Al buddy script is used to describe the functionality. in this case we simply described the $\mathrm{Al}$ buddy movement to follow the player if the distance exceeds five meters.

\section{Designing gameplay}

The team then laid out two of the game's game play sequences which was quite difficult when it came to what mechanics to use to make the puzzle work. We figured this out by trying out all available options and chose the most efficient game mechanics in Unity. This was by far the most time consuming task as creating gameplay scenes, and puzzles and mapping the story was not an easy task, the thought process was hard to do the first time but the whole team got involved which sped up the creative process.

\section{Conclusion}

After six months of development, the Usoni video game is now available on PC and Android, at a price of 3 dollars, and is presented as the first African post-apocalyptic game.

"Marc is French and is the creative director of the project, but it is a game created by African developers and we have appropriated this story as our own,"

points out Max Musau. We want to speak to Africans from Africa first, that's why the game will be translated into Swahili and French. "

First part of a trilogy.

Usoni alternates animation sequences that unfold the plot and platform game phases where you have to move your characters through a setting of post-industrial ruins while evading the surveillance of the intractable border police. The Kenyan game has the merit of making players - especially children and teenagers - aware of a large number of contemporary issues, while remaining first and foremost an easy-to-play action game.

The only drawbacks are the limited gameplay and the limited lifespan of the game. "With the skills we had in the team, we decided to create a platform game: the environment is in 3D but the characters can only move in one direction," admits Max Musau "however, for the next release, we will be in full $3 D$, which will also give more depth to the story. The game now available is only the first part of a trilogy.

In this opus, Ophelia and Ulysses try to escape from Europe. The next two parts will follow their adventures in Lampedusa - where Ophelia will be locked up in a refugee camp - and then across the African continent to Lake Turkana, in northern Kenya, the cradle of humanity.

In parallel, Marc Rigaudis and Max Musau are developing a second game based on the biography of the environmental activist Wangari Maathai, winner of the 2004 Nobel Peace Prize. Another African story that Jiwe wants to share with gamers in Kenya and elsewhere later this year.

\section{References}

USONI Tragédie Humaine by Marc Rigaudis (ed. L'Harmattan Paris 2019

THE LAST SONG (52 mn) by Marc Rigaudis TV5 2001 IMAGINE song by John Lennon

Girardot, Clement. 2021. Usoni, the first post apocalyptic african video game. Usbeketrica. https://usbeketrica.com/ fr/usoni-premier-jeu-video-africain-post-apocalyptique. Last access on 10/04/2021.

Ngila, Faustine. 2021. The team using video games to help fight climate change. The Daily Nation. https://nation. africa/kenya/business/technology/the-team-using-videogames-to-help-fight-climate-change-3266344. Last access on $10 / 04 / 2021$. 